\title{
Analisis Metode Clustering Pada Wilayah Berdasarkan Jenis Pencemaran Lingkungan Hidup
}

\author{
Fira Fania ${ }^{1}$, Mustika Azzahra ${ }^{2}$, Agus Perdana Windarto ${ }^{3}$ \\ Program studi Sistem Informasi, STIKOM Tunas Bangsa \\ firafania23@gmail.com ${ }^{1}$, mustikaazzahra37@gmail.com², \\ agus.perdana@amiktunasbangsa.ac.id
}

\begin{abstract}
This study uses a grouping model in determining areas based on the type of environmental pollution. This study is a special reference from the government in improving environmental sustainability. The data from this study was taken from the website of the government statistical data provider, BPS (Statistics Indonesia) www.bps.go.id. This research uses the K-Mens method and releases it with RapidMiner software to create 2 clusters, high and low level clusters and see what the contents of the cluster are. From the research results obtained by high cluster centroid data that is ((1527), (810.4), (5865), (6655.3), (323), (315.1)) low cluster namely ((139.25) , (122.5), (508,833), (919,222), (64,417), (94,444)). With this analysis, it is expected to be able to load and information for the government to pay more attention to regions whose income is still below average.
\end{abstract}

Keywords: Datamining, Clustering, K-Means, RapidMiner

\begin{abstract}
Abstrak
Penelitian ini bertujuan melakukan model pengelompokan dalam menetukan wilayah berdasarkan jenis pencemaran lingkungan. Penelitian ini menjadi referensi khususnya bagian pemerintah dalam meningkatkan kelestarian lingkungan.Data dari penelitian ini diambil dari sebuah website penyedia data statistic pemerintah yaitu BPS(Badan Pusat Statistik) www.bps.go.id. Penelitian ini menggunakan metode K-Mens dan diuji dengan software RapidMiner untuk membuat 2 kluster yaitu: kluster tingkat tinggi $(\mathrm{C} 1)$ dan rendah $(\mathrm{C} 2)$ dan melihat apa saja isi dari kluster tersebut. Dari hasil penelitian diperoleh centroid data kluster tinggi yaitu ((1527), (810,4), (5865), (6655,3), (323), (315,1)) kluster rendah yaitu $((139,25),(122,5),(508,833),(919,222),(64,417),(94,444))$. Dengan analisis ini diharapkan menjadi masukkan dan informasi bagi pemerintah untuk lebih memperhatikan daerah-daerah yang pendapatannya masih di bawah rata-rata.
\end{abstract}

Kata Kunci: Datamining, Klustering, K-Means, RapidMiner

\section{Pendahuluan}

Air merupakan salah satu yang utama bagi proses kehidupan di bumi, sehingga tidak ada kehidupan seandainya di bumi tidak ada air. Namun demikian, air dapat menjadi malapetaka bilamana tidak tersedia dalam kondisi yang benar, baik kualitas maupun kuantitasnya. Air yang relative bersih sangat didambakan oleh manusia, baik untuk keperluan hidup sehari-hari, untuk keperluan industri, untuk kebersihan sanitasi kota, maupun untuk keperluan pertanian dan lain sebagainya [1].

Pencemaran air yang terus meningkat telah menurunkan kualitas air di setiap wilayah.Pencemaran air disebabkan oleh jumlah manusia dan kegiatan manusia yang beragam. Pencemaran yang mengakibatkan penurunan kualitas air dapat berasal dari limbah industri,limbah usaha peternakan,perhotelan,rumah sakit,limbah pertanian,limbah perkebunan,domestik dan limba tersebar.Tingkat pemahaman masyarakat terhadap lingkungan hidup merupakan salah satu hal utama yang penting bagi berjalannya proses 
kegiatan. Upaya perbaikan pencemaran lingkungan hidup dapat dilakukan melalui dengan berbagai macam cara yaitu melakukan penyuluhan kepada masyarakat tentang pentingnya pelestarian lingkungan dan pencegahan serta penanggulan pencemaran lingkungan hidup. Secara fisik air layak dikonsumsi jika tidak berbau, berasa, maupun tidak berwarna. Di samping itu air tidak boleh mengandung racun maupun zatzat kimia berbahaya (syarat kimia), dan tidak mengandung bakteri, protozoa ataupun kumankuman penyakit. Oleh karena itu kebersihan dan terbebasnya air dari polutan menjadi hal yang sangat penting. Pencemaran air berdampak luas, misalnya dapat meracuni sumber air minum, meracuni makanan hewan, ketidakseimbangan ekosistem sungai dan danau, pengrusakan hutan akibat hujan asam, dan sebagainya.

\section{Metodologi Penelitian}

\subsection{Datamining}

Data mining adalah analisa terhadap data untuk menemukan hubungan yang jelas serta menyimpulkan yang belum diketahui sebelumnya dengan cara terkini dipahami dan berguna bagi pemilik data tersebut. Secara sederhana data mining bisa dikatakan sebagai proses penyaring atau“menambang" pengetahuan dari sejumlah data yang besar. Istilah lain untuk data mining adalah Knowledge Discovery in Database (KDD). Walaupun data mining sendiri adalah bagian dari tahapan proses KDD [2].

Berikut adalah flowchat dari K-means yang merupakan bagian dari datamining klastering seperti yang ditunjukkan pada gambar berikut:

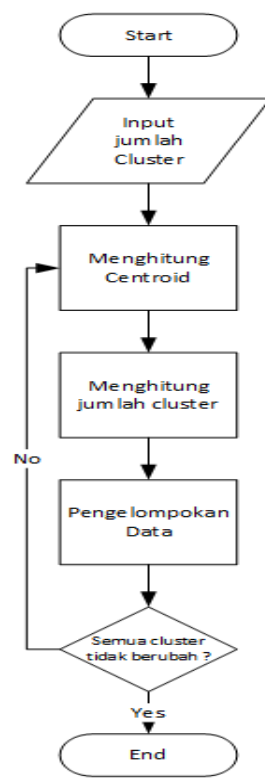

Gambar 1. Flowchat K-Means

Berdasarkan pada gambar 1, proses k-means secara garis besar adalah:

\section{a) Tahap pengumpulan data}

Sumber data penelitian diperoleh dari data yang dikumpulkan berdasarkan dokumen-dokumen yang dihasilkan oleh Badan Pusat Statistik Indonesia melalui situs https://www.bps.go.id.

\section{b) Tahap pengolahan data}

Data diolah menggunakan 2 cluster antara lain: cluster daerah pencemaran air tinggi (C1) dan cluster daerah pencemaran air rendah (C2)sehingga pada tahapan ini 
sudah diperoleh perhitungan nilai yang akan diproses pada tahap selanjutnya. Proses pengolahan menggunakan bantuan aplikasi RapidMiner.

\section{c) Tahap Clustering}

clustering merupakan metode pengelompokan data yang dimulai dengan mengelompokkan dua atau lebih yang memiliki kesamaan paling dekat. Kemudian proses diteruskan ke objek lain yang memiliki kedekatan kedua. Demikian seterusnya sehingga cluster membentuk semacam pohon dimana ada hierarki (tingkatan) yang jelas antar objek, dari yang paling mirip sampai yang paling tidak mirip [3][4].

\section{Hasil dan Pembahasan}

Dalam melakukan clustering, data yang diperoleh akan dihitung nilai rata-rata terlebih dahulu agar lebih mudah dalam pengolahannya seperti yang dapat dilihat pada table 1 .

Tabel 1. jumlah desa/kelurahan yang memiliki pencemaran air di Indonesia

\begin{tabular}{lrr}
\hline \multicolumn{1}{c}{ Provinsi } & $\mathbf{2 0 1 7}$ & $\mathbf{2 0 1 8}$ \\
\hline Aceh & 350 & 729 \\
Sumatera Utara & 449 & 1205 \\
Sumatera Barat & 144 & 319 \\
Riau & 318 & 454 \\
Jambi & 384 & 614 \\
Sumatera Selatan & 279 & 673 \\
Bengkulu & 189 & 286 \\
Lampung & 222 & 572 \\
Kep.Bangka Belitung & 152 & 159 \\
Kep.Riau & 28 & 55 \\
DKI Jakarta & 54 & 126 \\
Jawa Barat & 1131 & 1890 \\
Jawa Tengah & 932 & 1900 \\
Di Yogyakarta & 44 & 99 \\
Jawa Timur & 759 & 1643 \\
Banten & 251 & 513 \\
Bali & 82 & 130 \\
Nusa Tenggara Barat & 122 & 282 \\
Nusa Tenggara Timur & 53 & 122 \\
Kalimantan Barat & 717 & 915 \\
Kalimantan Tengah & 523 & 782 \\
Kalimantan Selatan & 445 & 714 \\
Kalimantan Timur & 249 & 318 \\
Kalimantan Utara & 59 & 139 \\
Sulawesi Utara & 140 & 327 \\
Sulawesi Tengah & 125 & 303 \\
Sulawesi Selatan & 176 & 400 \\
Sulawesi Tenggara & 73 & 227 \\
Gorontalo & 72 & 111 \\
Sulawesi Barat & 22 & 115 \\
Maluku & 57 & 105 \\
Maluku Utara & 46 & 216 \\
Papua Barat & 31 & 155 \\
Papua & 108 & 249 \\
\hline \multicolumn{1}{c}{ Sumber: BPS Indonesia } &
\end{tabular}

\subsection{Centroid Data}

Di dalam metode K-Means adapun penentuan cluster yang diinginkan. Penentuan cluster dibagi menjadi 2 titik yakni: tingkat tinggi (C1), tingkat rendah(C2). (C1) di 
dapat dari nilai maksimal suatu kriteria dan (C2) di dapat dari hasil nilai terendah dari suatu kriteria.Nilai kriteria tersebut dapat dilihat pada tabel berikut ini:

Tabel 2. Centoid Awal

\begin{tabular}{lrr}
\hline Centroid & A= Tahun 2018 & B= Tahun 2019 \\
\hline C1 & 1131 & 1900 \\
C2 & 22 & 55 \\
\hline
\end{tabular}

\subsection{Clustering Data}

Setelah didapat 2 titik centroid dari data yang ada selanjutnya akan melakuka proses iterasi 1 menggunakan 2 centroid data sebelumnya yang sudah ditentukan. Cluster tingkat tinggi $(\mathrm{C} 1)$ yaitu provinsi Jawa. Clushter tingkat sedang(C2) ada 18 provinsi dan Cluster tingkat rendah ada 13 provinsi. Hasil dari proses iterasi 1 bisa dilihat pada tabel 3 dan tabel 4 berikut ini:

Tabel 3. Perhitungan jarak pusat cluster

\begin{tabular}{|c|c|c|c|c|c|}
\hline Provinsi & 2017 & 2018 & C1 & $\mathrm{C2}$ & Jarak Terpendek \\
\hline Aceh & 350 & 729 & 1407,551775 & 749,5732119 & 749,5732119 \\
\hline Sumatera Utara & 449 & 1205 & 973,7294285 & 1226,714718 & 973,7294285 \\
\hline Sumatera Barat & 144 & 319 & 1863,794517 & 290,8264087 & 290,8264087 \\
\hline Riau & 318 & 454 & 1658,880647 & 496,8068035 & 496,8068035 \\
\hline Jambi & 384 & 614 & 1487,213838 & 665,9767263 & 665,9767263 \\
\hline Sumatera Selatan & 279 & 673 & 1493,798179 & 669,3078514 & 669,3078514 \\
\hline Bengkulu & 189 & 286 & 1868,785702 & 285,0438563 & 285,0438563 \\
\hline Lampung & 222 & 572 & 1609,305751 & 554,3365404 & 554,3365404 \\
\hline Kep.Bangka Belitung & 152 & 159 & 1997,378782 & 166,4812302 & 166,4812302 \\
\hline Kep.Riau & 28 & 55 & 2149,566003 & 6 & 6 \\
\hline DKI Jakarta & 54 & 126 & 2075,332503 & 77,87810989 & 77,87810989 \\
\hline Jawa Barat & 1131 & 1890 & 10 & 2144,086286 & 10 \\
\hline Jawa Tengah & 932 & 1900 & 199 & 2057,21292 & 199 \\
\hline DI Yogyakarta & 44 & 99 & 2103,608804 & 49,1934955 & 49,1934955 \\
\hline Jawa Timur & 759 & 1643 & 452,1426766 & 1750,689293 & 452,1426766 \\
\hline Banten & 251 & 513 & 1642,610422 & 512,0595668 & 512,0595668 \\
\hline Bali & 82 & 130 & 2057,498724 & 96,04686356 & 96,04686356 \\
\hline Nusa Tenggara Barat & 122 & 282 & 1906,831141 & 248,0503981 & 248,0503981 \\
\hline Nusa Tenggara Timur & 53 & 122 & 2079,271026 & 73,8241153 & 73,8241153 \\
\hline Kalimantan Barat & 717 & 915 & 1068,466658 & 1105,723745 & 1068,466658 \\
\hline Kalimantan Tengah & 523 & 782 & 1272,630347 & 882,9099614 & 882,9099614 \\
\hline Kalimantan Selatan & 445 & 714 & 1370,106565 & 783,0772631 & 783,0772631 \\
\hline Kalimantan Timur & 249 & 318 & 1811,255918 & 347,4161769 & 347,4161769 \\
\hline Kalimantan Utara & 59 & 139 & 2061,626785 & 91,78779875 & 91,78779875 \\
\hline Sulawesi Utara & 140 & 327 & 1859,142275 & 296,492833 & 296,492833 \\
\hline Sulawesi Tengah & 125 & 303 & 1887,444039 & 268,5386378 & 268,5386378 \\
\hline Sulawesi Selatan & 176 & 400 & 1778,208368 & 377,8107992 & 377,8107992 \\
\hline Sulawesi Tenggara & 73 & 227 & 1979,467858 & 179,4017837 & 179,4017837 \\
\hline Gorontalo & 72 & 111 & 2078,94252 & 75,07329752 & 75,07329752 \\
\hline Sulawesi Barat & 22 & 115 & 2101,453307 & 60 & 60 \\
\hline Maluku & 57 & 105 & 2091,769825 & 61,03277808 & 61,03277808 \\
\hline Maluku Utara & 46 & 216 & 2003,267581 & 162,7789913 & 162,7789913 \\
\hline Papua Barat & 31 & 155 & 2062,771194 & 100,4041832 & 100,4041832 \\
\hline Papua & 108 & 249 & 1942,248697 & 212,2074457 & 212,2074457 \\
\hline
\end{tabular}

Berdasarkan hasil perhitungan jarak pusat cluster pada tabel 3, dapat diambil pengelompokan untuk 1 iterasi seperti yang ditunjukan pada tabel berikut: 
Tabel 4. Pengelompokan Iterasi 1

\begin{tabular}{|c|c|c|}
\hline Provinsi & C1 & $\mathrm{C2}$ \\
\hline Aceh & & 1 \\
\hline Sumatera Utara & 1 & \\
\hline Sumatera Barat & & 1 \\
\hline Riau & & 1 \\
\hline Jambi & & 1 \\
\hline Sumatera Selatan & & 1 \\
\hline Bengkulu & & 1 \\
\hline Lampung & & 1 \\
\hline Kep.Bangka Belitung & & 1 \\
\hline Kep.Riau & & 1 \\
\hline DKI Jakarta & & 1 \\
\hline Jawa Barat & 1 & \\
\hline Jawa Tengah & 1 & \\
\hline Di Yogyakarta & & 1 \\
\hline Jawa Timur & 1 & \\
\hline Banten & & 1 \\
\hline Bali & & 1 \\
\hline Nusa Tenggara Barat & & 1 \\
\hline Nusa Tenggara Timur & & 1 \\
\hline Kalimantan Barat & 1 & \\
\hline Kalimantan Tengah & & 1 \\
\hline Kalimantan Selatan & & 1 \\
\hline Kalimantan Timur & & 1 \\
\hline Kalimantan Utara & & 1 \\
\hline Sulawesi Utara & & 1 \\
\hline Sulawesi Tengah & & 1 \\
\hline Sulawesi Selatan & & 1 \\
\hline Sulawesi Tenggara & & 1 \\
\hline Gorontalo & & 1 \\
\hline Sulawesi Barat & & 1 \\
\hline Maluku & & 1 \\
\hline Maluku Utara & & 1 \\
\hline Papua Barat & & 1 \\
\hline Papua & & 1 \\
\hline
\end{tabular}

Proses terus melakukan iterasi sampai hasil dari iterasi tersebut sama dengan hasil iterasi sebelumnya. Pada kasus ini proses iterasi berhenti pada iterasii ke 2 . Pada iterasi ke -2 dilakukan proses pencarian centroid data yang dapat dilihat pada tabel 5 berikut:

Tabel 5. Centoid Akhir

\begin{tabular}{lll}
\hline Centroid & A & B \\
\hline C1 & 797,6 & 1510,6 \\
C2 & 165,4483 & 320,4828 \\
\hline
\end{tabular}

Berikut adalah hasil dari proses iterasi terakhir pada perhitungan jarak pusat cluster yang dapat dilihat pada tabel berikut ini:

Tabel 6. Perhitungan jarak pusat cluster iterasi ke-2

\begin{tabular}{lrrrrr}
\hline \multicolumn{1}{c}{ Provinsi } & $\mathbf{2 0 1 7}$ & $\mathbf{2 0 1 8}$ & \multicolumn{1}{c}{ C1 } & C2 & Jarak Terpendek \\
\hline Aceh & 350 & 729 & 900,6910 & 448,2696 & 448,2696 \\
Sumatera Utara & 449 & 1205 & 463,5874 & 928,8554 & 463,5874 \\
Sumatera Barat & 144 & 319 & 1359,0819 & 21,4995 & 21,4995 \\
Riau & 318 & 454 & 1160,3533 & 202,7286 & 202,7286 \\
Jambi & 384 & 614 & 987,3989 & 365,9470 & 365,9470 \\
\hline
\end{tabular}




\begin{tabular}{lrrrrr}
\hline \multicolumn{1}{c}{ Provinsi } & $\mathbf{2 0 1 7}$ & $\mathbf{2 0 1 8}$ & \multicolumn{1}{c}{ C1 } & C2 & Jarak Terpendek \\
\hline Sumatera Selatan & 279 & 673 & 985,1496 & 370,3544 & 370,3544 \\
Bengkulu & 189 & 286 & 1367,4937 & 41,7582 & 41,7582 \\
Lampung & 222 & 572 & 1101,0383 & 257,7965 & 257,7965 \\
Kep.Bangka Belitung & 152 & 159 & 1497,8725 & 162,0418 & 162,0418 \\
Kep.Riau & 28 & 55 & 1646,5283 & 298,9534 & 298,9534 \\
DKI Jakarta & 54 & 126 & 1571,6419 & 224,1523 & 224,1523 \\
Jawa Barat & 1131 & 1890 & 505,0742 & 1842,7356 & 505,0742 \\
Jawa Tengah & 932 & 1900 & 411,9414 & 1755,6982 & 411,9414 \\
Di Yogyakarta & 44 & 99 & 1600,1648 & 252,5951 & 252,5951 \\
Jawa Timur & 759 & 1643 & 137,9120 & 1449,6053 & 137,9120 \\
Banten & 251 & 513 & 1137,5312 & 210,6703 & 210,6703 \\
Bali & 82 & 130 & 1555,0369 & 207,9598 & 207,9598 \\
Nusa Tenggara Barat & 122 & 282 & 1402,1032 & 58,0403 & 58,0403 \\
Nusa Tenggara Timur & 53 & 122 & 1575,6393 & 228,1228 & 228,1228 \\
Kalimantan Barat & 717 & 915 & 601,0289 & 810,9624 & 601,0289 \\
Kalimantan Tengah & 523 & 782 & 778,6290 & 583,8162 & 583,8162 \\
Kalimantan Selatan & 445 & 714 & 871,1477 & 482,7059 & 482,7059 \\
Kalimantan Timur & 249 & 318 & 1312,7287 & 83,5886 & 83,5886 \\
Kalimantan Utara & 59 & 139 & 1557,8243 & 210,3978 & 210,3978 \\
Sulawesi Utara & 140 & 327 & 1354,0113 & 26,2695 & 26,2695 \\
Sulawesi Tengah & 125 & 303 & 1382,2766 & 44,0648 & 44,0648 \\
Sulawesi Selatan & 176 & 400 & 1272,7211 & 80,2143 & 80,2143 \\
Sulawesi Tenggara & 73 & 227 & 1473,9994 & 131,4751 & 131,4751 \\
Gorontalo & 72 & 111 & 1576,5074 & 229,3809 & 229,3809 \\
Sulawesi Barat & 22 & 115 & 1596,6386 & 250,6004 & 250,6004 \\
Maluku & 57 & 105 & 1588,7730 & 241,2340 & 241,2340 \\
Maluku Utara & 46 & 216 & 1496,9608 & 158,6964 & 158,6964 \\
Papua Barat & 31 & 155 & 1557,3461 & 213,2156 & 213,2156 \\
Papua & 108 & 249 & 1437,7701 & 91,7065 & 91,7065 \\
\hline & & & & &
\end{tabular}

Berdasarkan hasil perhitungan jarak pusat cluster pada iterasi ke-2 sama dengan pengelompokan pada iterasi ke -1 yang ditunjukan pada tabel berikut:

Tabel 7. Pengelompokan Iterasi 2

\begin{tabular}{lrr}
\hline \multicolumn{1}{c}{ Provinsi } & C1 & C2 \\
\hline Aceh & & 1 \\
Sumatera Utara & 1 & \\
Sumatera Barat & & 1 \\
Riau & & 1 \\
Jambi & & 1 \\
Sumatera Selatan & & 1 \\
Bengkulu & & 1 \\
Lampung & & 1 \\
Kep.Bangka Belitung & & 1 \\
Kep.Riau & & 1 \\
DKI Jakarta & & 1 \\
Jawa Barat & 1 & \\
Jawa Tengah & 1 & \\
Di Yogyakarta & & 1 \\
Jawa Timur & 1 & \\
Banten & & 1 \\
Bali & & 1 \\
Nusa Tenggara Barat & & 1 \\
Nusa Tenggara Timur & & 1 \\
Kalimantan Barat & 1 & \\
\hline
\end{tabular}




\begin{tabular}{|c|c|c|}
\hline Provinsi & C1 & $\mathrm{C2}$ \\
\hline Kalimantan Tengah & & 1 \\
\hline Kalimantan Selatan & & 1 \\
\hline Kalimantan Timur & & 1 \\
\hline Kalimantan Utara & & 1 \\
\hline Sulawesi Utara & & 1 \\
\hline Sulawesi Tengah & & 1 \\
\hline Sulawesi Selatan & & 1 \\
\hline Sulawesi Tenggara & & 1 \\
\hline Gorontalo & & 1 \\
\hline Sulawesi Barat & & 1 \\
\hline Maluku & & 1 \\
\hline Maluku Utara & & 1 \\
\hline Papua Barat & & 1 \\
\hline Papua & & 1 \\
\hline
\end{tabular}

Hasil perhitungan menggunakan 2 centroid data pada iterasi ke -2 ternyata sama dengan hasil perhitungan pada iterasi ke -1 dan hal ini menandakan bahwa proses telah selesai. Dari proses tersebut didapat dari 34 provinsi bahwa terdapat 2 provinsi yang tergolong dalam populasi tingkat pencemaran air tinggi yaitu: Aceh, Sumatera Utara, Jawa Barat, Jawa Tengah dan Jawa Timur.lalu ada 13 provinsi yang tergolong dalam populasi tingkat pencemaran air yg rendah sedang dan 16 provinsi lainnya tergolong pada populasi rendah.

\section{Kesimpulan}

Dalam menentukan tingkat populasi desa/kelurahan yang memiliki pencemaran air berdasarkan provinsi dapat menggunakan clushtering dalam penghitungannya. Data tersebut diolah dengan bantuan software Microsoft Excel dalam proses perhitungannya. ditetapkan 2 cluster yaitu clushter tingkat tinggi dan rendah. Centroid untuk tingkat tinggi antara lain: (1527), (810,4), (5865), (6655,3), (323), $(315,1129,2308)$ dan centroid data tingkat rendah yaitu $(139,5313),(121,4375)$, $(486,5938),(818,9375),(64,0625),(98,1562)$. Sehingga dapat diperoleh hasil dari nilai centroid tersebut bahwa terdapat 2 provinsi yang tergolong dalam tingkat pencemaran air tinggi tinggi yaitu Aceh, Sumatera Utara, Jawa Barat, Jawa Tengah dan Jawa Timur. Sementara 16 provinsi lainnya tergolong pada populasi rendah. Hasil dari penelitian ini bisa jadi masukan kepada para pemerintah bahwa tingkat pencemaran air di indonesia masih sangat tinggi sekali melalui proses klastering yang telah dilakukan.

\section{Daftar Pustaka}

[1] D. D. A. N. Penanggulangannya and L. Warlina, "Pencemaran Air :," pp. 1-26, 2004.

[2] Cooper, “No 主観的健康感を中心とした在宅高齢者における 健康関連指標 に関する共分散構造分析Title,”pp. 5-10, 2019.

[3] A. Bastian et al., "Penerapan Algoritma," Jsi.Cs.Ui.Ac.Id, vol. 14, no. 1, pp. 2632, 2009.

[4] D. N. Batubara, A. P. Windarto, D. Hartama, and H. Satria, "Analisis Metode KMEANS Pada Pengelompokan Keberadaan Area Resapan Air Menurut Provinsi," no. $x$, pp. 345-349, 2019. 